\title{
A Re-evaluation of the Importance of the Lymphatic System in the Treatment of Post-mastectomy Lympboedema
}

\author{
AILEEN Z. GOODENOUGH \\ LAETITIA A. H. M. SCHEPERS
}

\section{SUMMARY}

The physiology and pathophysiology of the lymphatic system are discussed. Complex decongestive physiotherapy is presented as an alternative approach to the treatment of post-mastectomy lymphoedema. This is seen to be an effective method of treatment, but good patient compliance (hygienic measures, wearing elastic support while working, compression bandaging while at rest and remedial exercises), is a prerequisite. This may be achieved by intensive patient education.

\section{INTRODUCTION}

Like many other areas of medicine, the treatment of breast cancer has changed considerably during the last decade. A recent enquiry by the authors directed to physiotherapists in Natal, the Transvaal and Zimbabwe suggests that the physiotherapist is not always called upon to play a major role in the post-operative care of breast cancer patients. In this regard, it may be argued that the early post-operative role of the physiotherapist remains controversial, possibly due to over-enthusiastic exercise with resultant congestion of the tissues in the axilla. Surprisingly these enquiries also indicated that the greatest problem currently being experienced by such patients relates to lymphoedema - that is a high protein oedema of the arm on the operated side.

It has been suggested that the reason for the apparent increase in such incidences is that in some centres breast cancer patients are selectively being given the

Aileen Z. Goodenough, Nat. Dip. Phys.

Privale Praclitioner,

P.O. Box 255, Howick 3290

Laetitia A. H. M. Schepers, State Phys. (Netherlands)

No longer practising, 4 Palm Court, Sargeant Street, Greytown

\section{OPSOMMING}

Die fisiologie en patofisiologie van die limfatiese sisteem word bespreek. Saamgestelde dekongestiewe fisioterapie word as ' $n$ alternatiewe benadering tot die behandeling van namastektomie-limfedeem aanbeveel. Dit word beskou as 'n doeltreffende metode van behandeling. maar die resultate sal alleenlik behoue bly met die noue samewerking (higiëniese maatreëls, die dra van 'n rekbare mou gedurende die dag, drukverbande gedurende nagrus aanwend en oefeninge), van die pasiënt. Intensiewe opleiding van die pasiënt is noodsaaklik om goeie samewerking te bewerkstellig.

option of lump removal only. This is then followed by high doses of radiation to the axilla. Excessive fibrosis and scarring from these high radiation doses are thought possibly to contribute to the more frequent occurrence of lymphoedema. Further studies will be needed to evaluate this hypothesis more fully.

Reports on the incidence of post-mastectomy lymphoedema in the U.S.A. vary from $6,7 \%$ to $62,5 \%{ }^{1}$. It has never been explained why some mastectomy patients develop lymphoedema while others do not. Some may go for several years without lymphoedema, only to develop massive oedema later for no apparent reason. It has been suggested that multiple factors such as radiation therapy, infection, delayed wound healing, surgical ablation of lymphatic nodes and vessels, fibrosis from radiation or chronic oedema, thrombophlebitis, or inadequate regeneration of lymphatic vessels are possible etiological factors. ${ }^{2}$

The purpose of this article is, firstly, to take a fresh look at the physiology of the lymphatic system. Secondly, it highlights the concept of complex decongestive physiotherapy, as described by Földi, Földi \& Weissleder, ${ }^{3}$ as a worthwhile alternative method of treatment. It is the authors' view that this approach deserves consideration, in spite of the fact that it requires 
extensive patient education and a high level of patient compliance.

\section{PHYSIOLOGY}

\section{Normal Lymph Dynamics}

Guyton ${ }^{4}$ defines lymph as interstitial fluid that flows into the lymphatic system. The lymphatic system consists of pre-lymphatic channels in the interstitium, lymph capillaries, lymph collectors, lymph nodes and lymph trunks. They have valves along their larger vessels (collectors) up to the point where they empty into the circulation. The lymphatics also have minute "flap" valves that open into the interior of the lymphatic capillaries at their very tips. This means that substances of high molecular weight, such as proteins, can pass almost unimpeded into the lymphatic capillaries via the flap valves. Furthermore, there is no other route besides the lymphatics through which excess proteins can return to the circulatory system. ${ }^{4}$

An increase in interstitial fluid protein increases the tissue colloid osmotic pressure which disturbs normal capillary dynamics. Therefore, the most important function of the lymphatics, is to control the protein concentration in the interstitial fluid (Fig. 1).

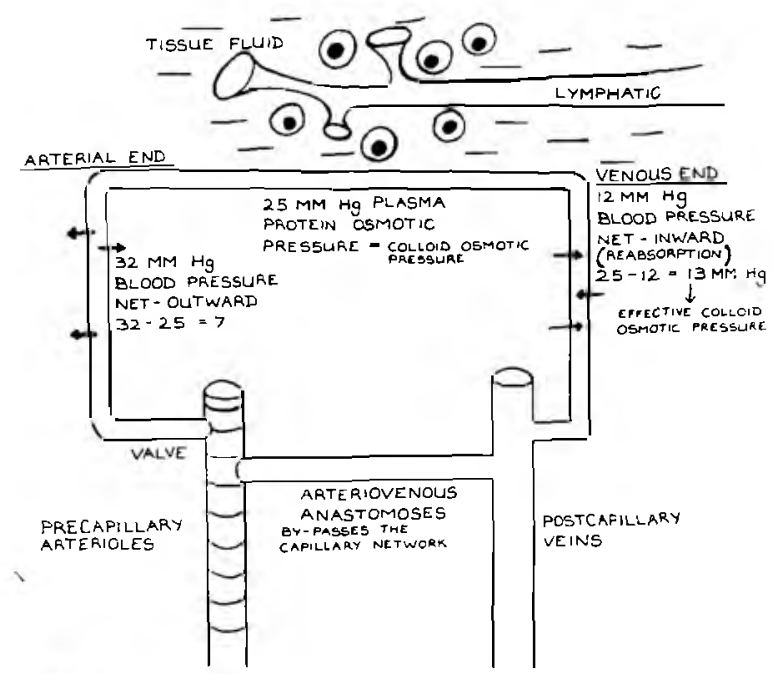

Fig.i. STARLING'S EXCHANGE HYPOTHESIS

The rate of lymph flow is determined by: ${ }^{4}$

(i) Interstitial fluid pressure

If the interstitial fluid pressure rises above its normal level it results in an increase in the flow of interstitial fluid into the lymphatic capillaries and consequently increases the rate of lymph flow. Factors, besides the obstruction to the lymph system itself, which tend to increase the interstitial pressure and therefore the rate of lymph flow, are elevated capillary pressure, decrease in plasma colloid osmotic pressure, increase in interstitial fluid protein and an increase in the permeability of the capillaries. This last point is important in selecting treatment techniques so as not to contribute to further tissue congestion.

(ii) The lymphatic pump

Compression of a lymph vessel or capillary from any source squeezes lymph forward along the lymph channels to the next valve in a pump-like manner. (A section of lymph channel from one valve to the next is called a lymphangion.) This pressure can be from the contraction of the smooth muscles in the walls of the lymphatics, or from external sources. These external pressures are the contraction of muscles, movement of body parts, arterial pulsations, breathing movements and the compression of tissue by objects outside the body; for example, gentle massage. The increase in lymph flow can be as much as 5 to 15 -fold during exercise. ${ }^{4}$ This is obviously an important factor in exercise-induced overloading.

\section{Oedema from Abnormal Capillary Dynamics ${ }^{4}$}

The cause of extracellular fluid oedema are:

(i) Increased capillary pressure causing an increase in the filtration of fluid through capillaries.

(ii) A decrease in plasma protein causing a decrease in the plasma colloid osmotic pressure and therefore a failure to retain fluid in the capillaries.

(iii) Lymphatic obstruction resulting in an increase in interstitial protein which increases the osmosis of the fluid out of the capillaries.

(iv) An increase in capillary permeability resulting in the leakage of excess fluid protein into the tissue spaces. This is the main reason for avoiding inflammatory processes in a congested limb.

\section{Response of Tissues to Secondary Lymphoedema after Mastectomy}

Lymphatic drainage into the axilla is partially or totally disrupted by surgery or subsequent radiation. Some women have cephalic lymph channels that drain into supra clavicular nodes. ${ }^{5}$ This can compensate for the lymphatic embarrassment and may be one of the reasons why these women do not develop any oedema of the arm. Regeneration is only possible if fibrosis does not mechanically and nutritionally limit new lymphatic formation. Premature drastic exercising, high doses of radiation and infection all play a role in exacerbating fibro-sclerotic changes in the tissues.

Földi and Földis state that before severe lymphatic obstruction develops certain compensatory mechanisms take place within the lymphatic system itself.

(i) Increase in volume-time ratio of collateral lymph vessels. In other words, the lymph transport capacity of the non-obstructed vessels increases.

(ii) The formation of anastomoses with nearby lymph vessels approximately three days after the lymph system is overloaded (lympho-lymphatic anastomoses). 
(iii) The creation of lympho-venous anastomoses with adjacent vessels.

(iv) The formation of longer pre-lymphatic channels.

(v) Extra lymph-vascular plasma protein mastering. Monocytes migrate from the capillaries into the lymphoedematous area. Here the monocytes change to become macrophages which attack the accumulating proteins thereby decreasing the lymphatic load. The macrophages release proteolytic enzymes which divide the proteins into amino-acids which are soluble and thus taken up by the blood circulation. This, however, only produces a marginal reduction of the oedema.

When these compensatory mechanisms fail more protein will steadily collect in the tissue spaces, increasing the colloid osmotic pressure. A protein-rich oedema thus forms, which is described as the first stage of lymphoedema. Three stages of this condition have been classified. ${ }^{3}$

Stage I: reversible lymphatic oedema which is a soft, pitting oedema.

Stage 2: spontaneously irreversible lymphatic oedema: when this stage is reached, the oedema can no longer be indented, fibrosis and sclerosis have taken place. The condition of the tissue deteriorates if left untreated. Chronic infection of the arm tissue compounds this problem, thus creating a vicious cycle leading to the third stage.

Stage 3: Lymphostatic Elephantiasis - swelling of limb in gross proportions. A possible complication of this stage is lymphangiosarcoma.

It is obvious that in the light of tissue physiology no swelling is meaningless and everything possible must be done to treat even the mildest degree of oedema.

\section{COMPLEX DECONGESTIVE PHYSIOTHERAPY ${ }^{3}$}

The aim of treatment is to restore the balance between lymphatic protein load and lymph vascular transport capacity, i.e. to restore the protein content of interstitial fluid to normal. This goal is achieved by helping the lymphatic system to remove the excess plasma proteins from the tissues using its own mechanics.

Treatment consists of four components, all considered to be of equal importance.

\section{Personal Hygiene}

Strict measures to limit inflammatory processes causing increased blood capillary permeability are vital. If contracted, any fungal or inflammatory condition must be vigorously combatted by the doctor concerned. This prevents overloading of the already disrupted lymphatic system.

\section{Manual lymph drainage}

This consists of a gentle massage technique whereby lymph is removed from the congested tissue.

The body has four lymphatic drainage quadrants, two axillary and two in the groin. The four trunk quadrants
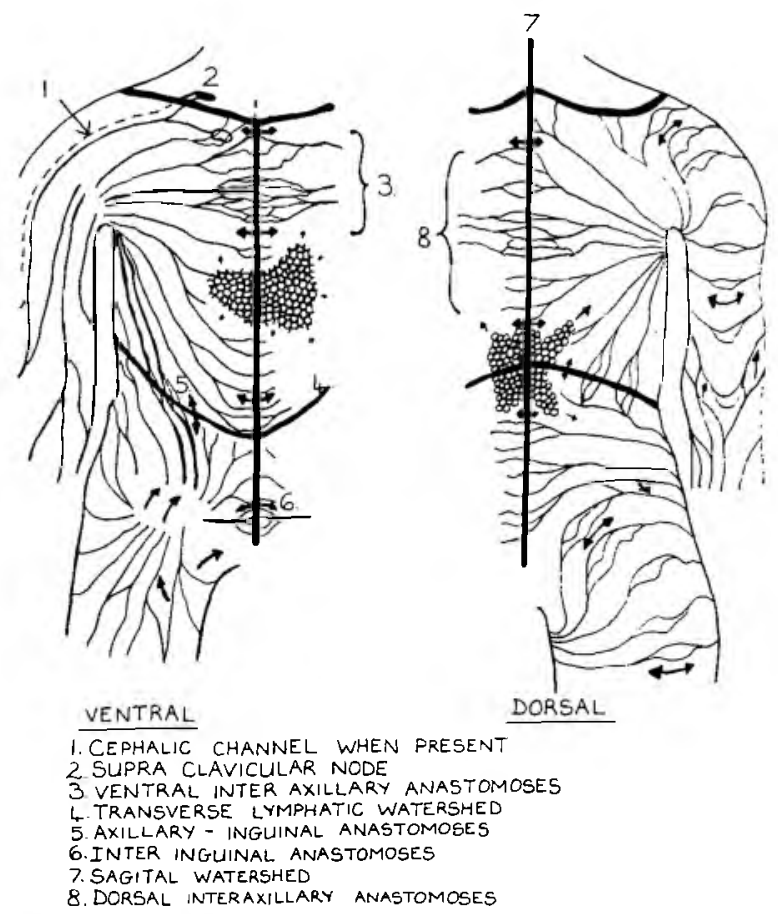

Fig.2. St Kubik: POSSIBLE WAYS OF DRAINAGE VIA SKIN

are separated by "lymphatic water-sheds" (Figure 2). There are some overbridging lymphatics in the upper quadrants which drain lymph into the axillary nodes on the opposite side. There are also connections between the lower quadrants and between the upper and lower quadrants on the same side. In most patients, postmastectomy lymphoedema includes the arm and the upper trunk according to the lymphatic drainage quadrant on the same side.

The first step in manual drainage is to stimulate lymphokinetic activity in the normal lymphatics of the healthy surrounding quadrants. This prepares them to cope with the increased load. It has been shown that lymphagions increase their output if subjected to mild mechanical stimuli. ${ }^{6}$ These dilated lymphatics will now start to drain the congested quadrant across the lymphatic watershed. This may take several treatments to establish.

The second step consists of gently pushing oedema fluid from the lymphostatic side across the watershed to the dilated healthy channels on the normal side. The upper arm can be emptied once the congested proximal part of the upper quadrant is free of oedema. Treatment of the forearm comes later and eventually includes the hand.

\section{Bandaging}

From the start of treatment bandages are applied to the lymphoedematous limb immediately after massage. One of the first pathological consequences of lymphoedema is the destruction of elastic fibres. 
The reduction of skin connective tissue elasticity compounds the drop in tissue pressure brought about by the fluid reducing massage. Consequently, the oedema fluid would simply re-accumulate unless supplemented by bandaging. Bandages also assist lymph flow by increasing tissue pressure.

\section{Exercises}

Exercises enable the muscle and joint pumps to exert their lympho-kinetic effect. There are important criteria ${ }^{5}$ to consider when working out a remedial exercise programme. The bandages must be worn during exercise. The exercises themselves must not be vigorous, cause excessive muscle fatigue or demand too much energy. These factors will increase the level of waste products and therefore the lymphatic load. Hydrotherapy is ideal because the hydrostatic pressure assists the tissue pressure. However, the water temperature must be carefully monitored to avoid vasodilation. Exercises must be comfortable and painfree and should not include sudden or ripping movements that could damage fragile, recovering tissue.

At the end of the treatment, when swelling is eliminated, an elastic support must be prescribed and made to measure. It must be as strong as can be tolerated by the patient.

It is of interest to note that Földi and his workers ${ }^{3}$ do not advocate the use of diuretics. This method leaves the stagnating plasma proteins in the tissue and will accelerate tissue hardening. They also have reservations about using pneumatic pump devices via inflatable cuffs (Jobst, Lymphapress etc). Their reasoning is based on the fact that it has been shown that the volume reduction is brought about by the re-absorption of water only. This means that the concentration of stagnating proteins in the interstitium increases. Once again this accelerates the fibro-sclerotic hardening of the tissues. Only approximately 20 per cent of their patients have pneumatic devices integrated into their complex decongestive treatment. This is done in order to replace some of the masseur's work. They also found that drug-induced stimulation of extra-lymph-vascular protein mastering (tissue proteolysis) is effective, but much slower than physiotherapy. ${ }^{3}$

\section{PATIENT EDUCATION}

A clear understanding by the patient of what is expected of her is critical to the success of this approach. The overall concept is to avoid excessive use of the arm, constrictive clothing, local or generalised heating and trauma.

Household advice ${ }^{5}$ should include taking extra care with sharp kitchen utensils or sewing pins to avoid piercing the skin. She should avoid washing dishes in water that is too hot or use gloves, and should always use potholders to take dishes from the oven or stove. It is better to avoid washing windows or carrying heavy parcels or bags with the affected arm. Extra care is necessary when ironing to avoid burns and for this reason cigarettes are best held by the unaffected hand. A tight wrist watch should not be worn on the affected arm and all housework should be done whilst wearing the prescribed glove stocking.

The patient's bra straps should never cut into her shoulders nor should the bra itself be too tight around the thorax. A lightweight prothesis also assists with this factor. Dress sleeves should be kept loose. Skin care incorporates careful manicures to avoid puncturing the skin; careful selection of cosmetics that are not too harsh for the skin; no suntanning or saunas and no "kneading" massage to the arm.

Other precautions include: suitable protective clothing while gardening, avoiding scratches and bites from pets, not letting the affected area be exposed to the heat of a hair dryer and preventive measures against insect bites. Sport should be of such a nature as to avoid over-exertion or potential injuries. Gentle controlled swimming is best.

Medical care should include: never using the B.P. cuff on the affected side or giving intravenous or intramuscular injections on that side; never taking blood from that arm or give acupuncture to it.

Good weight control with salt restriction, daily exercises in the prescribed sleeves and elevation of the limb at rest, all assist in maintaining the effect of the treatment.

Extensive patient education, as a prophylactic measure, should be given to all post mastectomy/post radiation patients. Emphasis should be placed on the need to consult a doctor for any infection or visible change in the affected arm. Early treatment of swelling will prevent a chronic condition from forming. However, chronic conditions also respond well to treatment, even in Stage 3.

\section{CONCLUSION}

By maximum utilisation of healthy and newly formed lymphatics, lymphoedema can be treated successfully. Complex decongestive physiotherapy normalises interstitial protein loads by increasing the transport capacity of the lymph vascular system. This volume reduction can be conserved by good patient compliance, that is by strict hygiene control, wearing of elastic sleeves and comprehensive bandaging during bed rest.

The importance of the lymphatic system in treating tissue congestion has, in the authors' view been a neglected area in physiotherapy.

\section{Footnote}

Video recordings on the subject are available in English from Beiersdorf AG, Hamburg, Germany.

These are:

1. 'Lymphoedema', order number LY101, 25 minutes, V.H.S. or Beta-U-matic.

2. 'Complex Decongestive Physiotherapy for Lymphoedema', order number LY 102, 20 minutes, V.H.S. or Beta-U-matic. 


\section{References}

1. Britton RC, Nelson PA. Causes and treatment of postmastectomy lymph-oedema of the arm: Report of 114 cases. JAMA 1962; 180: 95-102.

2. De Vita J Jnr, Hellman S and Rosenberg SA. Breast Cancer. In: Principles and Practice of Oncology. Philadelphia: Lippincott, 1982: 1741-1742.

3. Földi E, Földi $M$ and Weissledger $H$. Conservative treatment of lymphoedema of the limbs. Angiology. Jnl of Vascular Diseases March 1985; 171-180.

4. Guyton AC. The lymphatic system. In: Human Physiology and Mechanics of Disease. Philadelphia: W.B. Saunders Company, 1982: 237-241.

5. Földi $\mathrm{M}$ and Földi E. 'Das Lymphödem' Ein Leitfaden für Patienten. New York: Gustav Fisher Verlad-Stuttgart, 1983: 31-125.

6. Mislin H. The lymphagion. In: Lymphangiology, Ed by Földi M, Casley-Smith JR, Schattauer FK. New York, Stuttgart: 1983: 165.

For Orthopaedic Appliances,

Surgical corsets,

Cervical collars,

Children's shoes \& boots,

Artificial limbs,

Latest in plastic modification.

For Hiring and selling of

Hospital Equipment and

Sick room requisites -

Wheel chairs, walking aids,

Commodes,

Hospital beds,

Traction apparatus

Visit the orthopaedic mechanicians

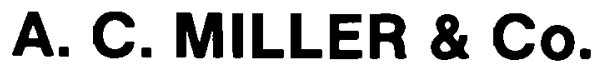

Technicians registered with the

S.A. Medical and Dental Council

275 BREE STREET JOHANNESBURG

Telephone (011) 337-4763

P.O. Box 3412 Johannesburg
BOOK REVIEWS

\section{Research Guidelines: A Handbook for Therapists}

by Cecily J. Partridge and Rosemary E. Barnitt

London: William Heinemann Medical Books, 1986

This reviewer has been waiting a long time for a book like this. Research Guidelines is written by a physiotherapist and an occupational therapist for therapists who wish to become involved in research, but do not know how to begin. In a clear, logical fashion the whole process of organising a research project is set out.

The first chapter describes the complete research process, while the chapters following elaborate on the individual areas viz. developing ideas, literature search, research design, organisation of the project, ethics, methods of data collection, etc. Throughout the book examples of research projects in physiotherapy and occupational therapy are used to illustrate the various facets of the process. The final chapters describe how to write the research report and how to evaluate published reports.

Some of the chapters include short reference lists. There is an excellent glossary of the most common terms used in research projects. A very useful bibliography is also included.

Research Guidelines is a small book with a great deal of pertinent information. It reads very easily. It is enlightening without being condescending. This book should be found on the library shelves of all physiotherapy schools as well as on the shelves of any therapist remotely interested in "research".

L. Davids

\section{Better Breathing}

by Z. Henryk Hrehorow

Winslow: Winslow Press, 1984

This short book is written primarily for the patient who experiences breathing difficulties as a result of chronic airway obstruction. The first edition was published in 1968. The new edition has been considerably revised.

The text has been very clearly set out with excellent photographs and diagrams. The language is simple and will be easily understood by the layman. The main concentration is on diaphragmatic breathing. The chapters cover - how and why we breathe, how to practice diaphragmatic breathing, relaxation, posture, overcoming breathlessness, cough and expectoration and exercises.

It would be useful to keep a copy of this book in the physiotherapy department for perusal by the chronic chest patient.

M. Farquharson 